\title{
Carotid artery stenting with or without distal filter-type embolic protection device: A single center experience
}

\author{
Ahmet Yabalak', Murat Yilmaz ${ }^{2}$ \\ ${ }^{1}$ Department of Neurology, Izzet Baysal State Hospital, Bolu, Turkey \\ ${ }^{2}$ Department of Neurology, Bolu Abant Izzet Baysal University, Faculty of Medicine, Bolu, Turkey
}

\section{ABSTRACT}

\begin{abstract}
Aim: To share the data of patients who underwent carotid artery stenting (CAS) with or without a distal filtertype (DF) embolic protection device (EPD) in our clinic and our own experiences.

Method: The files of patients who underwent CAS in our clinic between November 2019 and January 2021 were reviewed retrospectively. Patients with $>50 \%$ stenosis in symptomatic patients, $>70 \%$ in asymptomatic patients, and those who had CAS at least 48 hours after the last symptom were included. Patients who underwent acute CAS and were treated for restenosis after carotid stent or endarterectomy were excluded from the study. Thirty-five patients who used DF in CAS procedure and 16 patients who did not use EPD were included in the study.
\end{abstract}

Results: No significant difference was found between the two groups in terms of new neurological and cardiac vascular events $(p=0.58)$. A new ischemic lesion was detected in diffusion MRI in $76.5 \%$ of the patients who underwent CAS using a DF type EPD and $81.8 \%$ of patients who underwent CAS without the use of an EPD. No significant difference was found between the detection rates of new ischemic lesions $(p=0.73)$.

Conclusions: Since we found no significant difference in neurological and cardiac vascular events between the patients who underwent CAS with and without use of DF type EPD, we suggest that CAS can be performed without the use of a DF type EPD in suitable patients to reduce the cost of the procedure.

Key words: Carotid artery stenting, embolic protection device, distal filter, stroke, carotid artery stenosis.

Murat Yllmaz, Assist. Prof. M.D.

Bolu Abant Izzet Baysal University, Faculty of Medicine, Department of Neurology, 14030, Bolu, Turkey.

Email: dryilmazmurat@gmail.com

Received: 2021-07-14 / Revisions: 2021-08-07

Accepted: 2021-08-10 / Published online: 2021-11-01

\section{Introduction}

Carotid artery stenting (CAS) is a longestablished treatment for symptomatic and asymptomatic carotid stenosis. Currently, guidelines recommend CAS as an alternative treatment to carotid endarterectomy (CEA) operation in centers with a complication rate of less than $6 \%$ in symptomatic carotid stenosis and less than $3 \%$ in asymptomatic carotid stenosis [1]. It is known that in CAS, compared to CEA operations, the frequency of minor stroke is increased while the risk of myocardial infarction risk is decreased. No significant difference was found in terms of major ischemic events [2-4]. The advantages of CAS treatment compared to CEA are that it does not involve surgical incisions, there is no need for general anesthesia, there is no risk of cranial nerve damage, and cerebral perfusion can continue during the procedure in patients with contralateral stenosis and insufficient collateral flow through the Willis polygon [5]. The most 
prominent disadvantage is the risk of distal embolism at all stages of the procedure, such as crossing the stenosis with microwire, stent placement and angioplasty. Several embolic protection devices (EPD) have been produced and used to reduce the risk of distal embolism. Embolic protection devices are classified as distal occlusion balloons, distal filters (DF), and proximal occlusion devices (POD). Combined EPD applications are also available [5]. Many centers practice CAS procedure with EPDs. DF type embolic protection devices are the most widely used group in daily practice. While previous studies have reported that the risk of stroke is lower in patients with EPD; there are also publications reporting that there is no significant difference in risk of stroke, transient ischemic attack (TIA), and death between patients with and without EPD [6-9].

In this study, we wanted to share our experience and the data of our patients who underwent CAS with DF type EPD or without EPD in our center.

\section{Materials and Methods}

In this study, patient files who underwent CAS treatment between November 2019 and January 2021 in the comprehensive stroke center clinic of Abant Izzet Baysal Training and Research Hospital were retrospectively reviewed from hospital archive.

Patients included in this study were over 18 years of age, underwent CAS procedure within 48 hours of last symptom and had stenosis in carotid artery: according to North American Symptomatic Carotid Endarterectomy Trial (NASCET) criteria $>50 \%$ stenosis in symptomatic patients and $>70 \%$ stenosis in asymptomatic patients [10]. Patients who underwent acute CAS and were treated for old carotid stent or endarterectomy restenosis were excluded from this study. Out of 74 patients who underwent CAS in our clinic between the specified dates, 51 patients met our criteria and had their data analyzed (Figure 1).

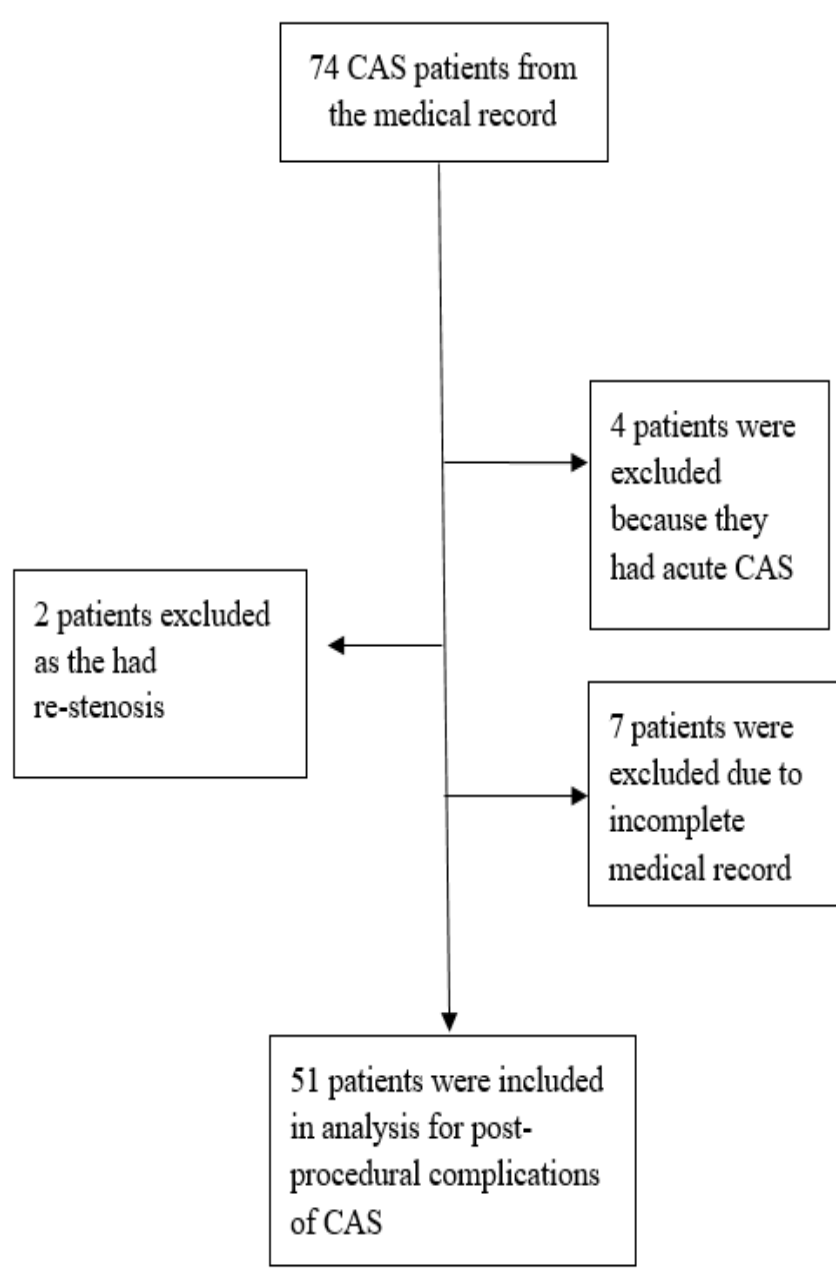

Figure 1. Flow chart.

\section{CAS procedure}

Patients received at least 5 days of Acetylsalicylic acid (ASA) $100 \mathrm{mg} /$ day and Clopidogrel 75 mg/day or ASA $100 \mathrm{mg} /$ day and Ticagrelor $90 \mathrm{mg} 2 \times 1$ treatments before undergoing the procedure. A $6 \mathrm{~F}$ guide catheter over an $8 \mathrm{~F}$ femoral sheath was used in the procedure. Patients were heparinized at a dose of 50/U $\mathrm{kg}$ to obtain activated clotting time within the therapeutic range. After the diagnostic angiography, stenosis measurements were made and symptomatic patients with $>50 \%$ stenosis and asymptomatic patients with $>70 \%$ stenosis underwent CAS procedure. 
Protege (Medtronic Corp.; Minneapolis, MN, USA) stent was used in all patients. During the procedure, pre-dilatation was performed in patients who did not have an opening through which the stent could pass, and post-dilatation was performed in patients with $>30 \%$ residual stenosis at the end of the procedure. The use of an EPD is also left to the operator's decision.

The data of 35 patients who underwent CAS with DF and 16 patients who underwent CAS without EPD were evaluated. Vascular risk factors of the patients, technical data related to the procedure, periprocedural complications, and cerebral and cardiac vascular events were noted. Imaging of 17 patients from the DF group and 11 patients from the group without EPD who had $1.5 \mathrm{~T}$ diffusion magnetic resonance imaging (MRI) (Signa Explorer, GE Healthcare, Chicago, IL, USA) before and in the first 24 hours after the procedure were evaluated. Newly developed ischemic lesions with a size of $<1 \mathrm{~cm}$ are indicated numerically. Patients with an infarct larger than one $\mathrm{cm}$ are noted as well. All patients were seen at the first month and third month follow-ups, and any newly developed cardiac and cerebral vascular events were noted and were evaluated for restenosis with Doppler USG. Primary outcome was determined as stroke and myocardial infarction whereas secondary outcome was determined as detection of a new ischemic lesion in diffusion MRI and increased number of ischemic lesions.

The study was approved by the Ethics Committee of Abant Izzet Baysal University. (02/03/2021, 79). After that, informed consent forms were obtained from the patients or their first-degree relatives, and then the data were evaluated.

\section{Statistical method}

Data were evaluated with SPSS 21.0 (IBM Corp.; Armonk, NY, USA) program.
Qualitative variables were expressed as numbers and percentages whereas quantitative variables were expressed as mean \pm SD. Quantitative variables with normal distribution between two independent groups were evaluated with the Independent Sample t test, and variables without normal distribution were evaluated with the Mann Whitney U test. Chisquare test was used when comparing categorical variables. A P value of $<0.05$ was considered statistically significant.

\section{Results}

The mean age of the patients within the DF group was $69 \pm 8.8$ (range; 50-90) years, and the mean age of the patients in the group without EPD was 70 \pm 8.6 (range; $54-83$ ) years ( $\mathrm{p}=0.48$ ). There were 27 male $(77.1 \%)$ and 8 female (22.9\%) patients in the DF group and 12 male $(75 \%)$ and 4 female $(25 \%)$ patients in the group without EPD. There was no significant difference between the two groups in terms of

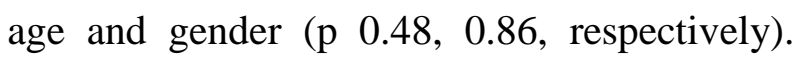
Hypertension (HT) was significantly more common in patients who did not use an EPD $(p=0.01)$. There was no significant difference between the two groups in terms of the frequency of diabetes mellitus (DM), hyperlipidemia (HL) and coronary artery disease (CAD) (Table 1).

Out of 35 patients in the DF group, $31(88.6 \%)$ received ASA $100 \mathrm{mg} /$ day + Clopidogrel $75 \mathrm{mg}$ treatment whereas the remaining 4 (\%11.4) received ASA $100 \mathrm{mg} /$ day + ticagrelor treatment. In the group without EPD, 15(\%93.8) patients received ASA $100 \mathrm{mg} /$ day + clopidogrel $75 \mathrm{mg}$ treatment and 1 (\%6.3) patient received ASA + ticagrelor treatment.

In the DF group, 5 (14.3\%) of the patients who underwent CAS had asymptomatic ICA stenosis compared to $3(18.8 \%)$ in the group 
without EPD. There was no significant difference between the ratios of symptomatic and asymptomatic patients between the two groups ( $\mathrm{p}=0.69)$. In DF group, stents are placed to the right ICA of 16 patients and left ICA of 19 patients. In the group without EPD, 7 patients had their right ICA stented whereas 9 patients had their left ICA stented.

Table 1. Comparison of patients' demographic data and vascular risk factors.

\begin{tabular}{|c|c|c|c|}
\hline Parameters & $\begin{array}{l}\text { DF Group } \\
n=35\end{array}$ & $\begin{array}{l}\text { Group } \\
\text { Without } \\
\text { EPD n=16 }\end{array}$ & $p$ \\
\hline Age (year) \pm SD & $69 \pm 8,8$ & $70,9 \pm 8,6$ & $0,48 *$ \\
\hline $\begin{array}{l}\text { Gender }(\mathbf{n}, \%) \text {, } \\
\text { (Male/Female) }\end{array}$ & $\begin{array}{l}27(77.1) / \\
8(22.9)\end{array}$ & $\begin{array}{l}12(75) / 4 \\
(25)\end{array}$ & $0,86^{* *}$ \\
\hline HT (n, \%) & $23(65.7)$ & $16(100)$ & $0,01 * *$ \\
\hline DM (n, \%) & $18(51.4)$ & $8(50)$ & $0,92 * *$ \\
\hline HL (n, \%) & $25(71.4)$ & $11(68.8)$ & $0,84 * *$ \\
\hline $\operatorname{CAD}(\mathbf{n}, \%)$ & $13(37.1)$ & $9(56,3)$ & $0,20 * *$ \\
\hline \multicolumn{4}{|c|}{$\begin{array}{l}\text { *Independent samples } t \text { test, ** Chi square test, DF. } \\
\text { Distal filter, EPD: Embolic protection device, CAD: } \\
\text { Coronary artery disease, DM : Diabetes mellitus, HL } \\
\text { Hyperlipidemia, SD: standard deviation }\end{array}$} \\
\hline
\end{tabular}

Balloon angioplasty was performed in 22 patients (\%62.9) from the DF group. Only predilatation was applied to 7 patients $(20 \%)$, only post-dilatation was applied to 8 patients (22.9\%), and both were applied to 7 patients (20\%). Balloon angioplasty was performed in 13 patients $(81.3 \%)$ from the group without an EPD. Two patients (12.5\%) underwent predilatation whereas $11(68.8 \%)$ patients underwent post-dilatation. There was no significant difference in balloon angioplasty application ratios between the two groups $(\mathrm{p}=0.18)$. The mean residual stenosis rates were detected as $13.4 \pm 10.5$ (range, $0-32$ ) in the DF group and $15.4 \pm 10.6$ (range, 0-40) in the group without EPD. There was no significant difference between residual stenosis rates ( $\mathrm{p}=0.53)$, (Table 2).

Table 2. Comparison of data on CAS.

\begin{tabular}{|c|c|c|c|}
\hline Parameters & $\begin{array}{l}\text { DF Group } \\
\mathrm{n}=35\end{array}$ & $\begin{array}{l}\text { Group } \\
\text { Without } \\
\text { EPD n=16 }\end{array}$ & $p$ \\
\hline $\begin{array}{l}\text { Symptomatic/ } \\
\text { Asymptomatic (n, \%) }\end{array}$ & $\begin{array}{l}30(85,7) / \\
5(14,3)\end{array}$ & $\begin{array}{l}13(81,2) / \\
3(18,8)\end{array}$ & 0,69 \\
\hline Right/ Left (n, \%) & $\begin{array}{l}16(45,7) / \\
19(54,3)\end{array}$ & $\begin{array}{l}7(43,8) / \\
9(56,3)\end{array}$ & 0,89 \\
\hline $\begin{array}{l}\text { Stenosis rate }(\%) \pm \text { SD } \\
(\text { min-max })\end{array}$ & $\begin{array}{l}77,2 \pm 10 \\
(57-95)\end{array}$ & $\begin{array}{l}67,7 \pm 10,6 \\
(55-95)\end{array}$ & 0,11 \\
\hline $\begin{array}{l}\text { Contralateral ICA } \\
\text { stenosis rate }(\%) \pm \text { SD } \\
(\text { min-max) }\end{array}$ & $\begin{array}{l}27,7 \pm 35,3 \\
(0-100)\end{array}$ & $\begin{array}{l}16,7 \pm 16,1 \\
(0-50)\end{array}$ & 0,25 \\
\hline Arcus type 1/2/3 (n, \%) & $\begin{array}{l}8(22,9) / \\
24(68,6) / \\
3(8,6)\end{array}$ & $\begin{array}{l}3(18,8) / \\
7(43,8) / \\
6(37,5)\end{array}$ & 0,05 \\
\hline $\begin{array}{l}\text { Residual Stenosis (\%) } \\
\pm \text { SD (min-max) }\end{array}$ & $\begin{array}{l}13,4 \pm 10,5 \\
(0-32)\end{array}$ & $\begin{array}{l}15,4 \pm 10,6 \\
(0-40)\end{array}$ & 0,53 \\
\hline Angioplasty rate (\%) & 62,9 & 81,3 & 0,18 \\
\hline
\end{tabular}

One patient in the DF group developed myocardial infarction 24 hours after the procedure and coronary stenting was performed by the cardiologist. Again, one patient in the DF group developed stent thrombosis during the procedure. The patient with total occlusion of the contralateral ICA was taken to acute endovascular recanalization and recanalization was achieved. However, the patient who developed a large bihemispheric infarct died on the 5th day of the procedure. In the group without EPD, TIA was detected in one patient and a minor stroke without disability was detected in another. There was no significant difference between the two groups in terms of new neurological and cardiovascular events $(p=0.58)$. Three $(8.6 \%)$ of the patients in DF group had vasospasm advanced enough to require vasodilator admission while the patients in EPD had no such problem (Table 3). 
Table 3. Periprocedural vascular complications.

\begin{tabular}{|c|c|c|c|}
\hline Parameters & $\begin{array}{l}\text { DF } \\
\text { Group }\end{array}$ & $\begin{array}{l}\text { Group } \\
\text { Without } \\
\text { EPD }\end{array}$ & $p$ \\
\hline $\begin{array}{l}\text { Vasospasm } \\
\text { (require } \\
\text { vasodilator) }(\mathbf{n}, \%)\end{array}$ & $3(8,6)$ & 0 & \\
\hline TIA (n, \%) & 0 & $1(6,3)$ & \\
\hline $\begin{array}{l}\text { Minor stroke (n, } \\
\%)\end{array}$ & 0 & $1(6,3)$ & \\
\hline Stroke (n, \%) & $1(2,9)$ & 0 & \\
\hline $\begin{array}{l}\text { Myocardial } \\
\text { infarction (n, \%) }\end{array}$ & $1(2,9)$ & 0 & \\
\hline $\begin{array}{l}\text { Stent thrombosis } \\
(\mathbf{n}, \%)\end{array}$ & $1(2,9)$ & 0 & \\
\hline Mortality (n, \%) & $1(2,9)$ & 0 & \\
\hline $\begin{array}{l}\text { Cardiac and } \\
\text { cerebral vascular } \\
\text { event }(n, \%)\end{array}$ & $2(5,7)$ & $2(12,5)$ & 0,58 \\
\hline
\end{tabular}

Table 4. Diffusion MRI findings.

\begin{tabular}{|c|c|c|c|}
\hline Parameters & $\begin{array}{l}\text { DF } \\
\text { Group } \\
\text { n=17 }\end{array}$ & $\begin{array}{l}\text { Group } \\
\text { Without } \\
\text { EPD } \\
\text { n=11 }\end{array}$ & $p$ \\
\hline New ischemic lesion (\%) & 76,5 & 81.8 & 0,73 \\
\hline $\begin{array}{l}\text { Number of new lesions } \\
\pm \text { SD }\end{array}$ & $3,8 \pm 5,6$ & $5,2 \pm 7,6$ & 0,61 \\
\hline Ipsilateral new lesion (\%) & 76,5 & 72,7 & \\
\hline $\begin{array}{l}\text { Number of ipsilateral new } \\
\text { lesions } \pm \text { SD }\end{array}$ & $3,6 \pm 5,7$ & $4,6 \pm 7,8$ & 0,94 \\
\hline $\begin{array}{l}\text { Contralateral new lesion } \\
(\%)\end{array}$ & 17,6 & 18,2 & \\
\hline $\begin{array}{l}\text { Number of contralateral } \\
\text { new lesions } \pm \text { SD }\end{array}$ & $0,1 \pm 0,5$ & $0,2 \pm 0,6$ & 0,82 \\
\hline $\begin{array}{l}\text { Posterior circulation new } \\
\text { lesion }(\%)\end{array}$ & 5,9 & 9,1 & \\
\hline $\begin{array}{l}\text { Number of posterior } \\
\text { circulation new lesions } \\
\pm \text { SD }\end{array}$ & 0 & $0,3 \pm 0,9$ & $\begin{array}{l}0,45 \\
* *\end{array}$ \\
\hline
\end{tabular}

MRI: Magnetic resonance imaging, DF: Distal filter, EPD: Embolic protection device,
Seventeen patients in the DF group and 11 patients in the group without EPD had diffusion MRI examinations before the procedure and within 24 hours after the procedure. When the imaging of these patients was evaluated, new ischemic lesions were detected in 13 patients (76.5\%) from the DF group and 9 patients $(81.8 \%)$ from the group without EPD. The mean number of new $<1 \mathrm{~cm}$ ischemic lesions in diffusion MRI was 3.8 \pm 5.6 in the DF group and $5.2 \pm 7.6$ in the group without EPD. There was no significant difference in the number of new ischemic lesions observed in diffusion MRI and the rates of detection of new lesions between the two groups ( $p$ 0.61, 0.73, respectively) (Table 4).

\section{Discussion}

In clinical practice, embolic protection devices are used in many centers, and DF type devices are the most widely used ones. Although embolic protection devices are extensively used, there are still authors who are skeptical about their effectiveness. According to the European Society for Vascular Surgery (ESVS) guideline [10], the use of EPD should be considered in patients undergoing CAS with a recommendation of Class IIa, Level B [11].

While there are publications in the literature reporting that the risk of stroke is lower in patients who use EPD during CAS procedure, there are also publications reporting that there is no significant difference between patients with and without EPD, and that new ischemic lesions are more common in patients who use EPD [7-9, 12-14].

In the randomized controlled study reported by Barbato et al. in which patients who underwent CAS with and without DF, diffusion MRI examination revealed that the new ischemic lesions were detected in $72 \%$ of the patients using DF and in $44 \%$ of the patients without 
EPD. There was no significant difference between the two groups. [7]. In a randomized study conducted by Macdonald et al., new ischemic lesions were found 24 hours after the procedure in the diffusion MRI of $29 \%$ of the patients who used DF and in $18 \%$ of patients in the group without EPD. The number of microembolic signals detected by transcranial Doppler USG during the procedure was found to be significantly higher in patients with DF [13]. In our study, no significant difference was found between the rates of new ischemic lesions in diffusion MRI examinations between patients with and without DF.

In the subgroup analysis of the Pro-CAS study reported by Theiss et al., no significant difference was found in mortality and stroke between 3543 patients with EPD and 1166 patients without EPD [13]. In a subgroup analysis evaluating patients in the CAS leg of the Multicenter International Carotid Stenting Study (ICSS), reported by Doig et al., major cardiac and cerebrovascular events within the first month were found in $8.5 \%$ of patients with EPD while they were found in $4.6 \%$ of the group without EPD; however, in terms of major cardiac and cerebrovascular events no significant difference was observed between the two groups [8]. In a meta-analysis study by Garg et al., stroke risk was found to be significantly lower in patients using EPD compared to patients not using EPD [9]. In a study by Knappich et al., in which the data of 13086 CAS cases were evaluated retrospectively, a significant reduction in the rate of stroke, mortality and duration of hospital stay was found with the use of EPD [12]. In a meta-analysis study, the number of new ischemic lesions detected was found to be significantly lower in patients who used EPD (33\%) compared to the group that did not (45\%) [14]. In our study, however, no significant difference was found between the two groups in terms of cardiac and cerebral vascular events. There was also no significant difference in terms of newly developed silent ischemic lesions.

In a study by Binning et al., CAS was performed without EPD in 174 patients and none of the patients developed neurological complications. In this study, post-dilatation was avoided, considering that distal emboli most likely develop during this phase. Despite this, the rate of restenosis requiring intervention in the follow-up of patients $(2.8 \%)$ remained low [16]. In our study, post-dilatation was performed when residual stenosis over 30\% was detected in patients. The reason for the relatively high presence of silent infarcts we found in our patients may be that the rate of total angioplasty was $68 \%$ and the rate of postdilatation was $50 \%$. While there are publications stating that PODs reduce the risk of embolism more than DF, there are also publications with a large number of cases reporting that there is no difference between them [17-19]. In the randomized study reported by Aytac et al. in which new ischemic lesions detected in post-procedure diffusion MRI examination were compared, new ischemic lesions were found at a rate of $65.4 \%$ in the DF group compared to $47.4 \%$ in those using POD, and no significant difference was observed [15]. In a meta-analysis comparing patients with POD or DF, Texakalidis et al. reported no significant difference in terms of mortality, TIA, and stroke risk [20]. In a randomized study reported by Montorsi et al., in which patients using randomized POD or DF, microembolic signals were evaluated with transcranial Doppler USG during the procedure and the number of MES was found to be significantly lower in those using POD [21]. POD was not used in our study. When the literature is 
reviewed, it is noteworthy that they are generally more successful than DFs in preventing silent ischemic lesions. [17, 19-21] Although CAS treatment has been in use for a long time, it is not possible to give a clear answer as to whether the use of EPD is necessary. There are conflicting results in studies investigating microembolic signals with transcranial doppler and post-operative new ischemic lesions with diffusion MRI. When evaluated in terms of clinically manifesting major embolic events, no significant difference was found in general [6-9, 12-13]. In our patients too, no difference was found between the two groups in the number of neurological and cardiovascular events or new ischemic lesions in diffusion MRI.

The advantages of our study are that silent infarcts were evaluated by imaging and the use of the same stent and DF in all patients. The disadvantages of our study are that the study was single-centered, the number of patients included in the study was small, diffusion MRI examination could not be performed in all patients, and the study was conducted in a retrospective nature.

\section{Conclusion}

While looking for an answer to the question of how to achieve embolic protection, it is necessary to evaluate many parameters such as collateral status, vascular tortuosity, stenosis rate, plaque morphology and make a choice according to the patient. We suggest that CAS can be performed without using DF, especially in patients who are thought to be unlikely to undergo pre-dilatation or post-dilatation considering pre-procedural radiological images and angiography imaging. While there is no change in the clinical outcome of the patients, the cost of the procedure can be reduced in this way. The answer to the questions of whether an EPD should be used and if so, what type should be used can only be possible with randomized controlled studies with a large number of cases comparing proximal protective devices, distal protective devices, combined method with each other.

Funding: The author(s) received no financial support for the research, authorship, and/or publication of this article.

Conflict of Interest: The authors declare that they have no conflict of interest.

Ethical statement: The study was approved by the Ethics Committee of Abant Izzet Baysal University (Date: 02/03/2021, Number: 79).

Open Access Statement

This is an open access journal which means that all content is freely available without charge to the user or his/her institution under the terms of the Creative Commons Attribution NonCommercial License (http://creativecommons.org/licenses/bync/4.0). Users are allowed to read, download, copy, distribute, print, search, or link to the full texts of the articles, without asking prior permission from the publisher or the author.

Copyright (c) 2021: Author (s).

\section{References}

[1]Kernan WN, Ovbiagele B, Black HR, et al. Guidelines for the prevention of stroke in patients with stroke and transient ischemic attack: a guideline for healthcare professionals from the American Heart Association/American Stroke Association. Stroke. 2014; 45(7): 2160-236.

[2]Ederle J, Dobson, J, Featherstone RL, et al. Carotid artery stenting compared with endarterectomy in patients with symptomatic carotid stenosis (International Carotid Stenting Study): an interim analysis of a randomised controlled trial. Lancet. 2010;375(9719):985-97. 
[3]Mas JL, Trinquart L, Leys D, et al. Endarterectomy Versus Angioplasty in Patients with Symptomatic Severe Carotid Stenosis (EVA-3S) trial: results up to 4 years from a randomised, multicentre trial. Lancet Neurol. 2008; 7(10): 885-92.

[4]Stingele R, Berger J, Alfke K, et al. Clinical and angiographic risk factors for stroke and death within 30 days after carotid endarterectomy and stent-protected angioplasty: a subanalysis of the SPACE study. Lancet Neurol. 2008; 7(3): 216-22.

[5]Bosiers M, Deloose K, Verbist J, et al. The impact of embolic protection device and stent design on the outcome of CAS. Perspect Vasc Surg Endovasc Ther: 2008; 20(3):272-79.

[6]Vos JA. Evidence overview: benefit of cerebral protection devices during carotid artery stenting. J Cardiovasc Surg (Torino). 2017; 58(2):170-77.

[7]Barbato JE, Dillavou E, Horowitz MB, et al. A randomized trial of carotid artery stenting with and without cerebral protection. J Vasc Surg. 2008; 47(4):760-65.

[8]Doig D, Turner EL, Dobson J, et al. Predictors of Stroke, Myocardial Infarction or Death within 30 Days of Carotid Artery Stenting: Results from the International Carotid Stenting Study. Eur J Vasc Endovasc Surg. 2016; 51(3):327-34.

[9]Garg N, Karagiorgos N, Pisimisis GT, et al. Cerebral protection devices reduce periprocedural strokes during carotid angioplasty and stenting: a systematic review of the current literature. J Endovasc Ther. 2009; 16(4):412-27.

[10]North American Symptomatic Carotid Endarterectomy Trial Collaborators, Barnett HJM, Taylor DW, Haynes RB, et al. Beneficial effect of carotid endarterectomy in symptomatic patients with high-grade carotid stenosis. N Engl J Med. 1991;325(7):445-53.

[11] Naylor AR, Ricco JB, de Borst GJ, et al. Editor's Choice - Management of Atherosclerotic Carotid and Vertebral Artery Disease: 2017 Clinical Practice Guidelines of the European Society for Vascular Surgery (ESVS). Eur J Vasc Endovasc Surg. 2018; 55(1):3-81.

[12]Knappich C, Kuehnl A, Tsantilas P, et al. The Use of Embolic Protection Devices Is Associated With a Lower Stroke and Death Rate After Carotid Stenting. JACC Cardiovas Interv. 2017; 10(12):1257-65.

[13] Macdonald S, Evans DH, Griffiths PD, et al. Filter-protected versus unprotected carotid artery stenting: a randomised trial. Cerebrovasc Dis. 2010; 29(3):282-89.

[14] Theiss W, Hermanek P, Mathias K, et al. Predictors of death and stroke after carotid angioplasty and stenting: a subgroup analysis of the Pro-CAS data. Stroke. 2008; 39(8):2325-30.

[15] Aytac E, Gürkaş E, Akpinar CK, et al. Subclinical ischemic events in patients undergoing carotid artery stent placement: comparison of proximal and distal protection techniques. J Neurointerv Surg. 2017; 9(10):933-36.

[16]Binning MJ, Maxwell CR, Stofko D, et al. Carotid Artery Angioplasty and Stenting Without Distal Embolic Protection Devices. Neurosurgery. 2017; 80(1):60-64.

[17] Touzé E, Trinquart L, Chatellier G, et al. Systematic review of the perioperative risks of stroke or death after carotid angioplasty and stenting. Stroke. 2009; 40(12):e683-93.

[18] Cho YD, Kim SE, Lim JW, et al. Protected versus unprotected carotid artery stenting: meta-analysis of the current literature. J Korean Neurosurg Soc. 2018;61(4):458-66. 
[19] Ielasi A, Latib A, Godino C, et al. Clinical outcomes following protected carotid artery stenting in symptomatic and asymptomatic patients. J Endovasc Ther. 2010; 17(3):298307.

[20] Texakalidis P, Letsos A, Kokkinidis DG, et al. Proximal embolic protection versus distal filter protection versus combined protection in carotid artery stenting: A systematic review and meta-analysis. Cardiovasc Revasc Med. 2018;19(5 Pt A):545-52.

[21]Montorsi P, Caputi L, Galli S, et al. Microembolization During Carotid Artery Stenting in Patients With High-Risk, LipidRich Plaque: A Randomized Trial of Proximal Versus Distal Cerebral Protection. J Am Coll Cardiol. 2011;58(16):1656-63. 